\title{
Fatigue limit by thermal analysis of specimen surface in mono axial traction test
}

\author{
A. Risitano ${ }^{1}$, G. Risitano $0^{2, a}$ and C. Clienti ${ }^{1}$ \\ ${ }^{1}$ University of Catania, Faculty of Engineering, Department of Industrial Engineering and \\ Mechanics, 95125 Catania, Italy \\ ${ }^{2}$ Guglielmo Marconi University, Faculty of Applied Sciences, 00153 Rome, Italy
}

\begin{abstract}
In this work is indicated how it could be possible to evaluate the limit stress of the thermo-elastic phase of deformation by thermo-analysing the surface of the specimen during a static traction test. Adding the temperature curve measured on a small area of the surface (the hottest) to the classic stress-strain curve, it is possible to evaluate a limit temperature $T_{0}$ coincident with the beginning of the non linear trend of the curve. The corresponding stress value is coincident with the fatigue limit of the analyzed component. As an example, the results of traction tests performed on two notched specimens, where the change of linearity in the temperature curve during static traction test was evident, are reported. The corresponding value of stress was a good approximation of the fatigue limit for $\mathrm{R}=-1$, determined by the conventional method. The aim of the reported examples in this paper must be interpreted as support to the basic principle of the method and not as the results of a complete experimental planning of which we will comment in an another occasion.
\end{abstract}

\section{Nomenclature}

$E_{l}$ energy required for fatigue fracture

$\Phi_{l}$ integral of a surface point temperature, proportional to $\mathrm{E}_{1}$, at fatigue fracture

$\sigma \quad$ stress

$\sigma_{0}$ fatigue limit for $\mathrm{R}=-1$ (limit stress above which some crystal is plasticized))

$\sigma_{i}$ minimum stress

$\sigma_{s}$ maximum stress

$\sigma_{m}$ mean stress

$\sigma_{p}$ plastic stress

$\sigma_{0,2}$ yield stress

$\sigma_{r}$ fracture strength/original cross sectional area and $\mathrm{t}_{\mathrm{r}}$ is the test time with thermo plastic behaviour

$f$ loading frequency

$R$ stress ratio

$\varepsilon \quad$ strain

$\varepsilon_{0}$ strain corresponding to $\sigma_{0}$

a e-mail : g.risitano@unimarconi.it

This is an Open Access article distributed under the terms of the Creative Commons Attribution-Noncommercial License 3.0, which permits unrestricted use, distribution, and reproduction in any noncommercial medium, provided the original work is properly cited. 
$\varepsilon_{p}$ medium plastic strain $\left(\varepsilon_{p}=\Delta l_{p} / l_{0}\right)$

$N$ current number of cycles

$N_{f}$ numbers of cycles to failure

$\alpha$ coefficient of linear thermal expansion

$T$ surface temperature

$T_{a}$ ambient temperature

$T_{0}$ "limit temperature" (corresponding to the end of the thermo-elastic phase)

$\Delta T$ temperature increment of the hottest area

$E$ modulus of elasticity

$v$ Poisson coefficient

$\rho$ density

$c_{\varepsilon} \quad$ specific heat for constant strain

$c_{\sigma} \quad$ specific heat for constant stress

$k_{c}$ thermal convection coefficient

$K_{m}$ thermo-elastic constant

$\Delta Q_{p}$ plastic energy released as heat

$d Q_{e}$ energy released as heat

$V_{e}$ volume elastically strained,

$V_{p}$ plastic volume

$V=V_{e}+V_{p}$ examined volume

$t_{0} \quad$ test time with thermo-elastic behaviour (corresponding to $\mathrm{T}_{0}$ )

$t_{r} \quad$ test time with thermo-plastic behaviour

$t_{f}=t_{0}+t_{r}$ complete test time

$v_{c} \quad$ velocity of the applied load

$V_{e} \quad$ volume $V$ in which the crystals are elastically strained,

$d V_{p}$ rate of the volume $\mathrm{V}$ plastically deformed $\left(\mathrm{d} \mathrm{V}_{\mathrm{p}}=\mathrm{V}-\mathrm{V}_{\mathrm{e}}\right)$

$S$ original cross sectional area of the specimen

$l_{0} \quad$ original length of the specimen

$\Delta l_{p} \quad$ plastic elongation

$d T_{e}$ temperature increment of elastic crystal in confront to ambient temperature

$d T$ temperature increment of the volume $\mathrm{V}$ in confront to ambient temperature

$\beta \quad$ Taylor coefficient

\section{Introduction}

Over the last 20 years, following the procedures devised by Locati $[1,2]$ and Prot $[3,4]$ to estimate the fatigue limit in short time and following Foppl's studies on the link between the internal damping and the fatigue resistance [5,6], many researchers have used the measurement of the specimen surface temperature during fatigue test to propose experimental methods to estimate the material fatigue limit. In particular, J F. Delorme et al. [7] studied the energy dissipated in a solid subjected to fatigue loading by measuring the temperature by means of semiconductor thermopiles. Dengel and Harig [8] used thermocouples to read the temperature during the fatigue test. Kaleta, et al. [9] used radiation thermometer and the energy released as heat was measured with an electric modelling method. In the same work the authors proposed a physical model to justify the fundamental assumption that the amount of energy needed to cause the fracture is constant independently of loading conditions. They noted also that the value of the fatigue limit was coincident with the first increase of the temperature. In 1984 Caltabiano et al [10 and 11] began to use thermograph to investigate the temperature surface during fatigue tests. They observed that under a load magnitude above the fatigue limit it was possible to localize the point where the specimen should fail. On the basis of the results reported in Refs [10 and 11], Curti, Risitano et al. [12 and 13] proposed a new method for the rapid determination of the fatigue limit. Risitano and La 
Rosa [14] proposed a method to determinate the fatigue limit using a very limited number of specimens (theoretically only one, three in practical applications). The specimen was loaded at different steps. The loads were applied progressively starting from the lowest to the highest. The analysis of the data was performed in the same way of Curti and Risitano [12]. Luong et al. [15-18] used the thermograph to measure the surface temperature and proposed a method similar to the one devised by Curti and Risitano [12]. Luong found the fatigue limit to be coincident with the load for which the temperature versus load curve changes the slop. The method uses two curves, one for stresses below the fatigue limit, the other for stresses above the fatigue limit. The stress corresponding to the intersection of the two curves was indicated as the fatigue limit. Blarasin et al.[19] using a method similar to the one proposed by Curti and Risitano[12] performed tests on a mechanical component (i.e, a connecting rod). Curà et al. [20] proposed a new iteration method as improvement of the Luong method to more accurately estimate the fatigue limit.

Starting from the hypothesis that the failure of a specimen (or a mechanical component) for fatigue stress occurs when the dissipated energy reaches a value $\mathrm{E}_{1}$ (limit energy) which is constant independently of loading conditions [7,9,21], Fargione et al. [22] proposed, for the first time, a new method (Risitano method) to determinate the fatigue curve (Wohler curve) of a material. By means of experimental control data performed in identical conditions (equal value of stress ratio $\mathrm{R}$ and test frequency f), it was verified that the value at the fatigue fracture of the energetic parameter $\left(\Phi_{1}\right)$, in the same away as $E_{1}$, remains constant independent from loading conditions. $\Phi_{1}$ is the integral of a surface point temperature (the hottest) during the high cycles fatigue test, for different value of the maximum stress (fig. 1). This permits one to associate the temperature of stabilization to the number of cycles to failure. In $2008 \mathrm{~F}$. Walter and D. Eifler [23] proposed a accelerated procedure for the determination of the Wöehler curve. They used a similar procedure as the one discussed in Ref [22] (step loads) in order to load the specimens and they measured the temperature of the specimen surface together with the electrical resistance of the specimen. By the Basquin equation which was adapted by the electrical measured parameters, they calculated the fatigue curve for a constant amplitude loading and random loading. All methods quoted above are based on the fact that in fatigue tests, from a thermal point of view, the elastic internal effect is negligible in comparison to the effect of the dissipative part associated with the fatigue behaviour. In 1995 Geraci et al [24] looked at the temperature of the steel specimens surface during static traction tests by infrared thermography to follow the trend. They noted the possibility to detect the thermoelastic effect and that the change of linear trend was independent from the applied speed rate.

On the basis of the hypothesis of Feltner and Morrow [21], confirmed by J F Delorme [7] and used by Kaleta et al. [9] and Risitano [22], Blonty and Kaleta worked both on mathematical model $[24]$ and in experimental way $[26,27]$ to study the energy expended in the material by determination of the heat energy released during the fatigue test. Atzori et al. $[28,29]$ studied the relation between the stress amplitude in fatigue tests, the specific heat loss and the fatigue life. Meneghetti [30] defined a theoretical model in order to determine the specific heat loss per cycle by surface temperature measurements during fatigue tests. Plekhev et al. [31] developed a thermodynamic internal variable model to analyze the plastic deformation localization in metals. The model allows to describe the stored and dissipated parts of energy under plastic flow. Klingbeil [32] linked the fatigue crack growth with the total plastic energy dissipation per cycle obtained by elastic-plastic finite element simulation of the fatigue tests. Boulangeret et al. [33] used the calorimetric analysis to estimate the thermoelastic energetic part and the dissipative part during fatigue tests of steel specimen. Ranc et al [34] studied the propagation of the crack in the gigacycles fatigue regime developing a thermomechanical model. They observed by infrared analysis that the propagation stage of the crack constitutes a small part of the lifetime of the specimen. Selek et al.[35] studied the crack initiation by artificial neural networks using thermographical temperature profiles of AISI 37 under reverse bending. Lazzarin et al. [36] studied the local energy density in welded joint and the value of the strain energy averaged over a well-defined control volume was given in closed form. Chrysochoos and Louche [37] analyzed the temperature surface by infrared camera during a static traction test of a flat and thin parallelepiped sample. By using an infrared image processing based on Fourier's techniques, they observed a sudden dissipative effect due to the propagation of the Luders 
band during the local plastic deformation. In 2009 Plekhov and Naimark [38] with the use of a high sensitivity infrared camera, demonstrated that in static traction test the plastic deformation is accompanied by emergence of heat waves and their propagation over the specimen surface were therefore studied.

In this complex scenario, aim of the present paper is to devise a method for the evaluation of the fatigue limit of a material or of a structural component by thermographic analysis of a simple static tests and not of more complicate and expensive fatigue tests. The use of high precision thermal sensors, able to read the temperature surface with $0,02 \mathrm{C}^{\circ}$ precision, allowed the authors to analyze the trend of temperature during a static traction test. The potentiality of the image analysis system permitted to follow the variation of the temperature at any point of the specimen surface during the test. Therefore, in this work, it is proposed, for the first time (as far as the authors are aware) a method to define the fatigue limit of a material or a mechanical component by the thermo analysis of the surface temperature of the specimen (component) during a classic uni-axial tensile static test. The stress at which the thermo-elastic phase finishes gives a good estimate of the value of the fatigue limit for a stress ratio $\mathrm{R}=-1$.

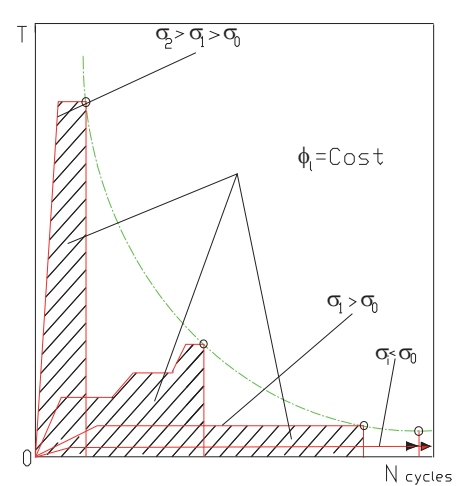

Fig1. Parameter $\Phi_{1}$ for different load $\left(\sigma_{\mathrm{i}}\right)$

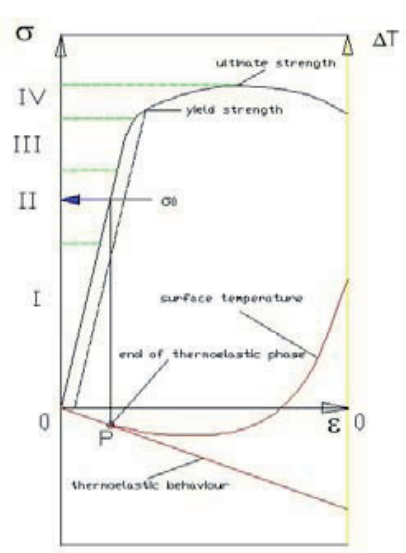

Fig. 2. Stress-strain and temperature curve

\section{The temperature in static tensile test}

It is known that fatigue failures occur at those points where the local stress is able to give plastic deformation. In fact, in the points where there are micro-defects (structural or superficial) the stresses are intensified in comparison to the average stress value (load/area) and are reached local stress conditions that result in fatigue failures. Therefore, in different manner than the traditional definition, we can define as fatigue limit of the material, the average value of stress (load/area) in a monoaxial traction test, for which, at some point of the material, plastic local conditions are reached, conditions which are not visible by classic instrumentation, but only through a deep thermal surface analysis.

It is known also that during a static tensile test, the micro-plasticization process zone is the II in figure 2. Following the I zone, where the average stress is so low that every crystal is stressed into the elastic field, in the II zone the average stress has a value so that the most part of the crystals are interested by elastic deformations, but some crystals are plastically deformed. Following the removal of the load, the specimen returns to the same macroscopic condition. In terms of thermal behaviour of the material during a tensile static test, we can distinguish two phases:

- the first phase in which all crystals are deformed in an elastic field (zone I in figure 2). In this phase, the relation stress-strain is linear.

- the second phase in which not all crystals are deformed in an elastic field, and only some are deformed in the plastic field (zone II in figure 2). 
In the first phase, the behaviour of the material follows the thermo-elasticity theory [40]. As it is already known, for an elastic body the stress-strain law can be written as:

$$
\{\sigma\}=[C](\{\varepsilon\}-\{\alpha\} \Delta T)
$$

where $\alpha$ is the thermal elongation coefficient, $\Delta T$ is the temperature variation of the material and $C$ is the stiffness matrix.

Under the hypothesis of adiabatic phenomena, for a static traction test of isotropic material, being $\sigma=\sigma_{m}$ constant at any point of the specimen, the first thermodynamic law leads to:

$$
\Delta T=-K_{m} T \sigma_{m}
$$

In this phase, the surface temperature shows a linear decrement during the application of the tensile load. If for the applied stress $\sigma_{p}$ (lower than $\sigma_{0,2}$ ) a plasticity condition in some defected point (small volume $d V_{p}$ ) of the material volume $V$ is reached, at this point the Eq. (2) is no longer valid and the effect of the dissipative plastic deformation is associated with a thermal energy $d Q_{p}$ that changes the linear trend of the temperature during the application of the load. Therefore, there will be a part ( $\left.V_{e}=V-d V_{p}\right)$ of the volume $V$ that will follow the linear elastic law, and a part $d V_{p}$ that, in a hypothesis of an ideal plastic condition, adds heat, i.e. $d Q_{p}=\beta \sigma_{p} d \varepsilon_{p}$. ( $\beta$ Taylor coefficient). With the increase of the stress, the plastic deformation in the volume $d V_{p}$ grows and at the same time, in other crystals, the plasticization process begins and consequently also the heat contribution. In this phase, the quantity of heat is a function of the stress, of the local strain law, of the increase in time of deformation, and of the distribution in the volume $V$ of the plasticization process during the time.

In the literature there are many analytical and numerical models that link the damage with energy and thermal variation for fatigue loading [25-36] and for static tensile test [37,38] and the hypothesis concerning the plasticization model, internal heat and external transmission, can help to find qualitative solutions only. Following the above easy engineering model, using the similar conditions assumed for the thermo-elasticity theory (adiabatic phenomena are accepted even at moderate strain rates), following the thermoelastic phase, the temperature vs test time can be written as:

$$
T=-K_{m} T_{a} \sigma_{r}\left(t / t_{r}\right)+\left[\beta \sigma_{0} \varepsilon_{p}\left(t / t_{r}\right)^{2}\right] / \rho c_{\varepsilon}+\left[K_{m} T_{a} \sigma_{r}\left(t / t_{r}\right)^{3}\right] / 3
$$

With the symbols reported in "Nomenclature", it was assumed:

$$
\varepsilon=\varepsilon_{0}+t \varepsilon_{0} / t_{0}, \quad \varepsilon_{p}=\Delta l_{p} / l_{0}=v_{c} t_{r} / l_{0}, \quad v_{c}=t \sigma_{r} S / t_{r} \quad V_{p}=t^{2} V / t_{r}{ }^{2} \quad V_{e}=V-t^{2} V / t_{r}{ }^{2}
$$

and $\beta=0,9$ (constant) even if it is known that the Tailor coefficient is not constant particularly in the first strain rates $[42,43]$. As it will be seen, the equation (3) fits the experimental results very well. If we would be able to capture the first plastic heat in relation to the external average stress applied, we could find the stress that produces the first plastic damage in the specimen and therefore the conventional fatigue limit for $\mathrm{R}=-1$. In fact, if this stress were applied in a fatigue test of the specimen, the specimen would fail; instead, for fatigue stress under this value, the specimen would not reach the failure point. This remark suggests that the fatigue limit can be found by the individualisation of the first plasticization at which a internal heat is released and consequently a surface increment of the temperature follows. Therefore by a static traction test, using adequate instrumentation and test conditions, it is possible to find the fatigue limit stress $\sigma_{0}$ (average value of the external applied stress) through the determination of the "temperature limit" $\mathrm{T}_{0}$, where $\mathrm{T}_{0}$ is the temperature for which in a stress (strain) vs. temperature curve the linear trend finishes, therefore, for the first time, a variation of the derivate is noted (figure 2).

Following the elastic phase, the number of crystals plasticized increases with the load and after reaching the stress yield, the heat production is so much that the elastic effect of the elastic deformed crystals is masked and the surface temperature therefore reaches positive values. In figure 
2, in qualitative form, a stress-strain curve and the corresponding temperature-strain curve with the indication of $\mathrm{T}_{0}$ and the fatigue limit $\sigma_{0}$ is reported.

\section{Testing procedure for the experimental determination of $T_{0}$ and $\sigma_{0}$}

Following what it is said above, it is possible to have an experimental definition of temperature $\mathrm{T}_{0}$ and consequently of the zone where the plasticization appears for the first time. The increase in temperature depends on the material characteristics (for steel at an ambient temperature of $23^{\circ} \mathrm{C}$ there is an increase of approximately $0,1^{\circ} \mathrm{C}$, for each $100 \mathrm{~N} / \mathrm{mm}^{2}$ of stress), on the sensibility of the thermal sensors, on the image analysis quality, on the signals synchronization of the three parameters (load, elongation and surface temperature).

As a general indication, we can say that during the first phase (perfectly elastic) for which at any point of the surface is $\Delta T=-K_{m} T \sigma_{m}$, the temperature variations are proportional to the thermoelastic coefficient $K_{m}$ (approximately $3,3 \times 10^{-12}\left[\mathrm{~Pa}^{-1}\right]$ for steel and $10 \times 10^{-12}\left[\mathrm{~Pa}^{-1}\right]$ for aluminium alloy) and to the point value of the stress. The temperature variations are more evident near the high stress concentration point.

The authors used the method before reported in different cases to verify the fatigue limit $\sigma_{0}$ finding values in sound agreement with those determined by means of traditional methods [44] or Risitano's methods [14] for $R=-1$. As an example, here an application of the method to the steel $\mathrm{Fe}$ 36 notched specimen (figure 3) is reported. The testing machine was Instron model $8501100 \mathrm{kN}$ Servo Hydraulic Machine and The thermographic scanner was Flir System model SC-3000. The image processing was also performed by Flir system. The frequency of image acquisition was 1 $\mathrm{imm}$./s. The emissivity coefficient was 0,98 . In figure 4 , the load-elongation curve of the specimen is reported. The test velocity adopted for the tensile test was $22 \mathrm{~N} / \mathrm{s}$. In figure 5 , the load vs time and the corresponding curve temperature vs time are reported. The temperature was that of the surface point near the hole boundary. In the same figure, the temperature found by equation (3) for equal value of load velocity and with the test values of $\varepsilon_{0}=0,0014$ and $\varepsilon_{\mathrm{p}}=\Delta l_{\mathrm{p}} / l_{0}=0,04$ is reported. In this case it is very evident the gradient's change and it is easy to determine $T_{0}$ and consequently, the corresponding load [5,8 kN]. The fatigue limit load, determined by traditional method for $R=-1$, was $5,7 \mathrm{kN}$. As an example, the figure 6 shows 4 (at the beginning of the test, at the middle of the test, before the failure, and at the failure) of the circa 2400 test recorded images. In figure 7 is reported the test curves for a specimen different from the previous one only for the working (smooth surface) of the hole. In this case, the load velocity was twice the one of the previous test [44N/s], i.e. $\varepsilon_{0}$ $=0,0024$ and $\varepsilon_{p}=0,04$. The value of the load corresponding to the change of gradient pointed in the figure was $[9 \mathrm{kN}$ ] and the fatigue load limit for $\mathrm{R}=-1$ found by traditional method and Risitano's method was 9,1. Also in this case the analytical curve fitted the experimental curve well.

As in the previous example, the figure 8 shows 4 of the images recorded during the test.

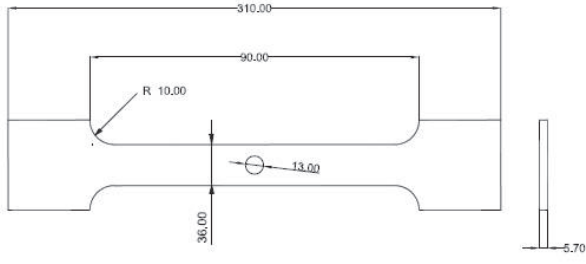

Fig. 3. Dimensions (mm) of the specimens

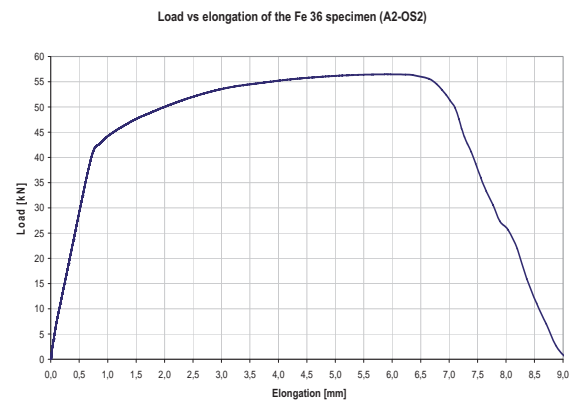

Fig. 4. Load vs elongation of the Fe 36 specimen 

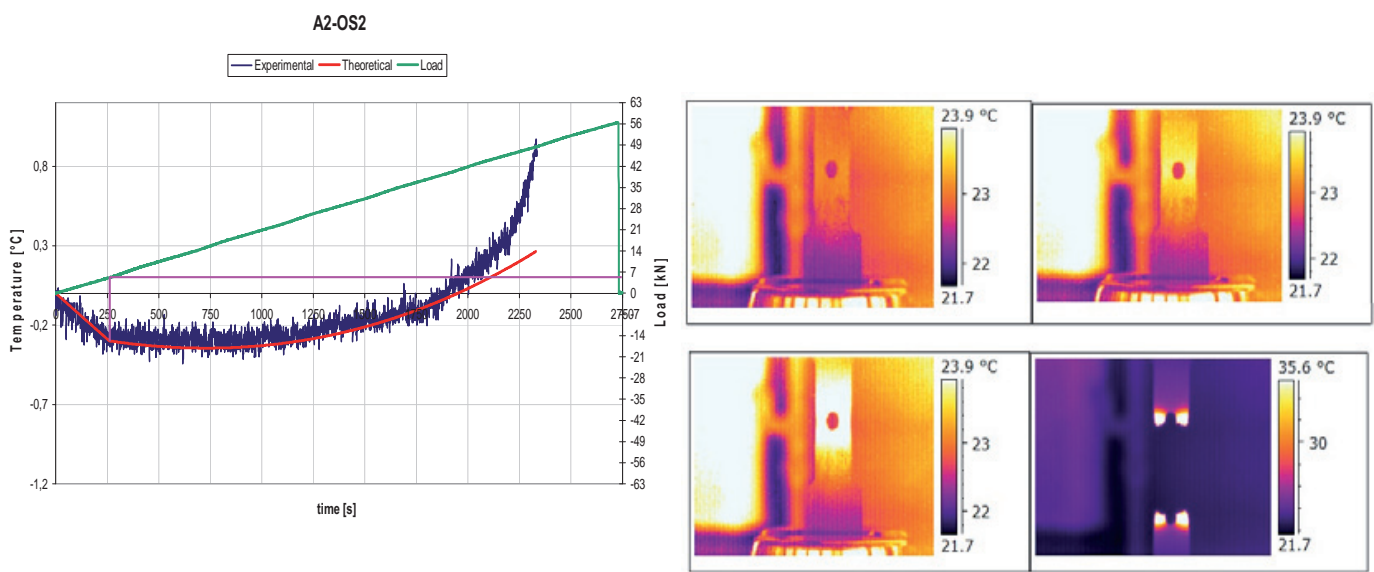

Fig. 5. Temperature evolution curves.

Fig. 6. Thermographic images of the specimen
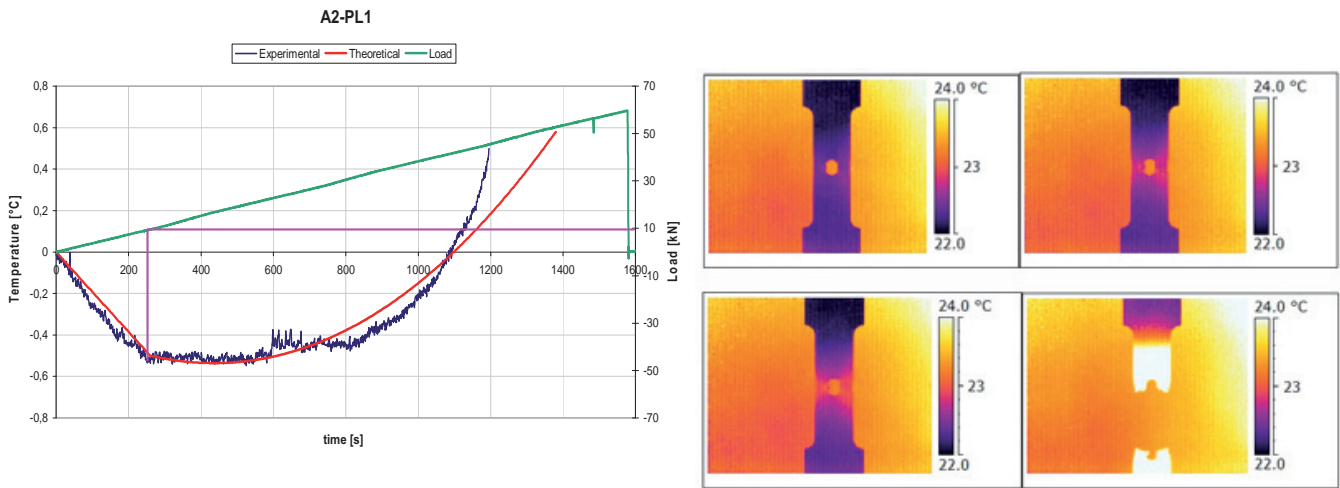

Fig. 6. Temperature evolution curves.

Fig. 8. Thermographic images of the specimen

\section{Conclusions}

The thermal analysis in static and dynamic test can efficiently aid to characterize the mechanical properties of engineering materials.

The Authors in this work propose a method to estimate the fatigue limit of a material (or a mechanical component) by thermographic analysis of a simple traction static tests.

The method is completely different from the others proposed by other authors that use cyclic loading. In fact, the fatigue limit $\sigma_{0}$ can be found by the individualisation of stress $\sigma$ able to produce the first plasticization at which internal heat is released and consequently a change of the linear trend of the surface temperature occurs .

According to this method, the traction stress $\sigma_{0}$ corresponding to the end of the linear decrease of the local temperature of the most critical point (the hottest), is a good approximated value of the fatigue limit for $\mathrm{R}=-1$.

As an example, final diagrams for two applications are reported. In these applications the reading of the fatigue limit is particularly clear and in a good approximation with that found by the traditional method and by Risitano method. 


\section{References}

1. Locati L. "An aid for the determination of fatigue limit in research and production" Metall. Ital. 27, 188-204 (in Italian) 1935

2. Locati L. "Fatigue and other tests with progressively increasing load" Eng.Dig 20, 337,339 1959

3. Prot M. The "The determination of the fatigue limit by progressively increased loading", Misure et control 13, 301-309 1948 (in French)

4. Prot M. The "Fatigue testing under progressive loading", WADCTR 53-148 (1952)

5. Föppl O.” Die Dämpfungsfägsfähikeit eines Baustahles bei Wechselbeanspruchungen”, V.D.I.Z., vol. 70 n.39, 1291-1296, (1926)

6. Föppl O. Ludwik P. "Stoffprüng-Wege zu einer Wirklichkeitsgetreuen Festgkeitsrechnung", V.D.I.Z., vol. 76 n.14,683-685, (1932)

7. J F Delorme, G Sinicki and P Gobin, Calorimetric study of the energy dissipated from a solid subjected to fatigue cycles $1968 \mathrm{~J}$. Phys. D: Appl. Phys. 1 1737-1742

8. D. Dengel and H. Harig, Estimation of the fatigue limit by progressively-increasing load tests, Fatigue Fract Eng Mater Struct 3 (1980), pp. 113-128

9. J. Kaleta, R. Blotny and H. Harig, Energy stored in a specimen under fatigue limit loading conditions, J Test Eval 19 (1990), pp. 326-333

10. T. Catalbiano, A. Geraci and M. Orlando, Analysis of the fatigue strength of specimens by means of the infrared technique, Il Progettista Industriale (1984), p. 2. (in Italian)

11. Geraci A., La Rosa G., Risitano A, L'infrarosso termico nelle applicazioni meccaniche, CRES Symposium, Catania Italy, 1984, published in ATA Ingegneria Automotoristica 1985,38 (8-9),

12. Curti G.,La Rosa G.,Orlando M., Risitano A. Analisi tramite infrarosso termico della "temperatura limite" in prove di fatica AIAS XIV Convegno Nazionale Catania Italy, 1986

13. Curti G., Geraci A., Risitano A. Un nuovo metodo per la determinazione rapida del limite di fatica, ATA Ingegneria Automotoristica (in Italian), 10, 634-636, 1989

14. G. La Rosa, A. Risitano, Thermographic methodology for rapid determination of the fatigue limit of materials and mechanical components, International Journal of Fatigue n.22, pp. 65-73

15. M.P. Luong, Fatigue limit evaluation of metals using an infrared thermographic technique, Mech Mater 28 (1988), pp. 155-163

16. M.P. Luong, Infrared thermography of fatigue in metals, SPIE 1682 (1992) pp.222-223

17. M.P. Luong, K Dang-Van, Metal fatigue limit using infrared thermography Atti della fondazione G. Ronchi, anno IL (1993)

18. M.P. Luong, Infrared scanning of fatigue in metals, Nucl Eng Des 158 (1995), pp. 363-376

19. A. Blarasin, R. Fracchia and M. Pozzati, Rapid determination of the fatigue limit of materials and components by means of the infrared technique, ATA - Ingegneria Automotoristica 51 (5) (1988), pp. 255-265.(in Italian)

20. F. Curà, G. Curti and R. Sesana, A new iteration method for the thermographic determination of fatigue limit in steels, Int J Fatigue 27 (2005), pp. 453-459

21. C.E. Feltner and J.D. Morrow, Microplastic strain hysteresis energy as a criterion for fatigue fracture, Trans. ASME, Ser. D: J Basic Eng 83 (1961), pp. 15-22

22. G. Fargione, A. Geraci, G. La Rosa and A. Risitano, Rapid determination of the fatigue curve by the thermographic method, International Journal of Fatigue 24 (2002), pp. 11-19

23. F. Walter, D.Eifler, Short-time procedure for the determination of Wöehler and fatigue life curves using mechanical, thermal and electrical data, Journal of Solid Mechanics and Materials Engineering, Vol. 2 No. 4,2008

24. A. Geraci, G. La Rosa and A. Risitano, Correlation between thermal variation in static test and elastic limit of material using infrared imagery, $7^{\text {th }}$ International conference on mechanical behaviour of material, The Hague May 28- 2June 2, 1995

25. Blonty R and Kaleta "Analysis of Mathematical model of the Fatigue Energy Hypothesis as seen by identification theory" PhD Thesis, Inst. of material Science and Appl. Mechanics, TU Wroclaw, Report No 199,1978 (in Polish) 
26. Blonty $\mathrm{R}$ and Kaleta "A mhethod for determination the heat energy of fatigue process in metal under Uniaxial stress:part 2-Measurament of the temperature of a fatigue specimen by means of thermovision camera computer system. International Journal of Fatigue Vol.N1, 1986 pp35-38

27. Blonty R and Kaleta " The accumulated internal energy in fatigue strength region, Proceedings, 7h International Conference on fracture (ICF-7) Houston Tex., 20-24 March 1989, Pergamon Press, Oxford, pp1195-1202

28. Atzori B, Gasparini E, Meneghetti G. Thermographic analysis of the fatigue strength of metallic materials. In: Proceedings of 30th AIAS national conference; 2001. p. 367-76 (in Italian)

29. B. Atzori and G. Meneghetti, Energy dissipation in low cycle fatigue of austempered ductile irons. LCF 5. In: P.D. Portella, H. Sehitoglu and K. Hatanaka, Editors, Proceedings of the 5th international conference on low cycle fatigue, DVM, Berlin (2003), pp. 147-152

30. G. Meneghetti, Analysis of the fatigue strength of a stainless steel based on the energy dissipation, International Journal of Fatigue Volume 29, Issue 1, January 2007, Pages 81-94

31. O.A. Plenkev, N. Saintier, T. Palinluc, S.V. Uranov and Naimark, "Theoretical analysis, infrared and structural investigations of energy dissipation in metals under cyclic loading, Material Science and Engineering Vol 462, Issues 1-2, 25 July 2007, Pages 367-369

32. N.W. Klingbeil, A total dissipated energy theory of fatigue crack growth in ductile solids, Int $J$ Fatigue 25 (2003), pp. 117-128

33. T. Boulanger, A. Chrysochoos, C. Mabru and A. Galtier, Calorimetric analysis of dissipative and thermoelastic effects associated with the fatigue behaviour of steels, Int. J. of Fatigue 26 (2004), pp. 221-229

34. N. Ranc D. Wagner and P.C. Paris Study of thermal effects associated with crack propagation during very high cycle fatigue tests, Acta Materialia Volume 56, Issue 15, September 2008

35. M. Selek, Ö. S. Şahin and Ş. Kahramanl, Thermographical Investigation of Crack Initiation Using Artificial Neural Networks EUROCON 2007 The International Conference on "Computer as a Tool" Warsaw, September 9-12

36. Lazzarin P, Livieri P, Berto, F. et Al. Local strain Energy density and fatigue strength of welded joint under uniaxial and multiaxial loading, Engineering fracture mechanics, volume 75 Issue: 7 Pages 1875-1889, 2008

37. A. Chrysochoos, H. Louche, An infrared image processing to analyse the calorific effects accompanying strain localisation, International Journal of Engineering Science n. 38 1759-1788

38. O.A. Plenkov, O B. Naimark, Theoretical and experimental study of Energy dissipation in the course of strain localization, Journal of applied mechanics and technical physics, vol. 50 No. 1, pp 127-136, 2009

39. W.Nowacki, Thermoelasticity $2^{\circ}$ edition, Pergamon Press, Oxford, New York, Toronto, Sydney, Paris, Frankfurt 1986

40. G. La Rosa, G. Mirone, A. Risitano "Effect of stress triaxiality corrected plastic flow on ductile damage evolution in the framework of CDM", Journal of Engineering Fracture Mechanics, 2001,V. 68, p. 417-434

41. G. La Rosa, G. Mirone, G. Risitano, "Previsione di rottura duttile in condizioni di triassialità disuniforme e variabile", AIAS XXXVI Convegno Nazionale, Napoli, 4-8 settembre 2007

42. Guruswami Ravichandran, Ares J. Rosakis, Jon Hodowany and Phoebus Rosakis, On the conversion of plastic work into heat during High- strain deformation, CP620 Shock Compression of condesed Matter-2001 - 2002 American Institute of Physic

43. H.L. Schereyer and P.J. Maudlin, Thermodinamically consistent relations involving plasticity, internal energy and thermal effects, http/:rsta.royalsocitypubblishing,org/content/3631836/2517

44. ASTM E 466-72 Standard practice for conducting constant amplitude axial test of metallic materials 